\title{
Níveis de Vitamina C e Ferro para Tilápia do Nilo (Oreochromis niloticus)
}

\section{Margarida Maria Barros ${ }^{1}$, Luiz Edivaldo Pezzato², Geisa Karine Kleemann³, Hamilton Hisano ${ }^{3}$, Guilherme Jordão de Magalhães Rosa ${ }^{4}$}

\begin{abstract}
RESUMO - Os efeitos de diferentes níveis de vitamina $\mathrm{C}$ e ferro no desempenho produtivo e parâmetros fisiológicos da tilápia do Nilo (Oreochromis niloticus) foram avaliados por um período de 73 dias. O delineamento foi inteiramente casualizado, com tratamentos dispostos em esquema fatorial com três níveis de vitamina C (125; 375 e $1115 \mathrm{mg} / \mathrm{kg})$ e três níveis de ferro $(30,90$ e $270 \mathrm{mg} / \mathrm{kg}), \mathrm{mais}$ um tratamento adicional $(0 \mathrm{mg} / \mathrm{kg}$ de suplementação de vitamina $\mathrm{C}$ e ferro), com quatro repetições cada tratamento, totalizando 10 grupos experimentais. Utilizaram-se 240 alevinos revertidos com peso médio inicial de 7,46 $\pm 0,49 \mathrm{~g}$, distribuídos aleatoriamente em 40 aquários de $250 \mathrm{~L}$, numa lotação de 6 peixes/aquário. Confeccionou-se dieta purificada com 32,0\% de proteína bruta e $3300 \mathrm{kcal} / \mathrm{kg}$ de energia digestível. A ausência de vitamina $\mathrm{C}$ e ferro nas dietas propiciou o aparecimento de anemia microcítica e hipocrômica aos alevinos. A presença dessa vitamina em dosagens elevadas estimulou a liberação de eritrócitos imaturos na corrente sangüínea. Determinou-se, também, que níveis desses acima das exigências nutricionais descritas para a espécie não determinaram efeito detrimental no desempenho produtivo, na produção de proteínas plasmáticas ou nos aspectos morfológicos do fígado.
\end{abstract}

Palavras-chave: Oreochromis niloticus, vitamina C, ferro, hematologia, desempenho produtivo

\section{Levels of Vitamin C and Iron for Nile Tilapia (Oreochromis niloticus)}

\begin{abstract}
The effects of different levels of vitamin C and iron on growth performance and physiological parameters on Nile tilapia (Oreochromis niloticus) were evaluated for 73 days. A factorial experiment with three levels of vitamin C $(125 ; 375$ e $1115 \mathrm{mg} / \mathrm{kg})$ and three levels of iron $(30,90$ e $270 \mathrm{mg} / \mathrm{kg}$ ), plus an additional treatment (with $0 \mathrm{mg} / \mathrm{kg}$ of vitamin $\mathrm{C}$ and iron), was considered on a completely randomized design, with four replicates for each experimental group. It was randomly stocked 240 reverted fingerlings, an average weight of $7.46 \pm 0.49 \mathrm{~g}$, into $40,250 \mathrm{~L}$, aquaria at a density of 6 fish/aquarium. A albumin-gelatin-diet was formulated to contain $32.0 \%$ of crude protein and $3,300 \mathrm{kcal} / \mathrm{kg}$ of digestible energy. Fingerlings of Nile tilapia fed diet without supplemental vitamin $\mathrm{C}$ and iron developed hypochromic microcytic anemia and the supplemental vitamin $\mathrm{C}$ determined the presence of immature erythrocytes on blood. It was also determined that iron serum concentration was influenced by vitamin $\mathrm{C}$ and iron supplied on diets, and that levels above to nutritional requirements for the specie did not determined detrimental effect on growth performance, plasmatic protein or morphologic characteristics of liver.
\end{abstract}

Key Words: Oreochromis niloticus, vitamin C, iron, hematology, growth performance

\section{Introdução}

A vitamina $C$ assume importância considerável em razão de ação em vários processos metabólicos. Essa vitamina é considerada essencial para a maioria das espécies de peixes, uma vez que não a sintetizam em função da ausência da enzima L-gulonolactona oxidase para sua formação a partir da glucose (Lovell, 1998). No entanto, o mineral ferro destaca-se, essencialmente, por sua participação em processo respiratório celular (NRC, 1993). Em função da baixa disponibilidade desse mineral no ambiente aquático, a ração passa a ser a fonte principal desse para os peixes.
Entre os principais aspectos avaliados para esses nutrientes, em diferentes espécies e fases do desenvolvimento dos peixes, destaca-se a ação deles no desempenho produtivo, na resistência a doenças, nas respostas imunológicas, nos parâmetros hematológicos e nas respostas ao estresse.

A interação desses nutrientes tem sido alvo de estudo em função da atuação do ácido ascórbico no metabolismo do ferro. A vitamina $\mathrm{C}$ evita a formação de compostos insolúveis e auxilia, também, na absorção desse mineral, reduzindo-o no estômago, ao estado ferroso, forma esta, absorvível. Participa, ainda, na liberação do ferro da transferrina e ferritina, o qual é

\footnotetext{
1 Zootecnista Depto. Nutrição e Melhoramento Animal, FMVZ - UNESP - Botucatu - SP - CEP: 18.618-000 - Caixa postal 560. E.mail: mbarros@fca.unesp.br

2 Prof. Adjunto Depto. Nutrição e Melhoramento Animal, FMVZ - UNESP - Botucatu.

${ }^{3}$ Alunos de Pós-Graduação da FMVZ.

4 Prof. Dr. Department of Animal Science and Department of Fisheries and Wildlife, Michigan State University, USA.
} 
subseqüentemente, incorporado à hemoglobina ou a outros compostos essenciais (Devlin, 1998).

Dessa forma, essa pesquisa foi conduzida com o objetivo de estudar os efeitos de diferentes níveis de vitamina $\mathrm{C}$, de ferro e a interação deles no desempenho produtivo e parâmetros fisiológicos em tilápia do Nilo.

\section{Material e Métodos}

A pesquisa foi desenvolvida no Laboratório de Nutrição de Organismos Aquáticos da Faculdade de Medicina Veterinária e Zootecnia - UNESP, Câmpus de Botucatu, laboratório esse associado ao Centro de Aqüicultura da UNESP.

$\mathrm{O}$ experimento foi inteiramente casualizado em esquema fatorial 3 x 3, com três níveis de vitamina $C$ e três níveis de ferro, e um tratamento adicional (ausente de suplementação de vitamina $\mathrm{C}$ e ferro), com 4 repetições cada, totalizando 10 grupos experimentais. Foram utilizados 240 alevinos de tilápia do Nilo com peso médio inicial de 7,46 $\pm 0,49 \mathrm{~g}$, distribuídos aleatoriamente em 40 aquários de $250 \mathrm{~L}$, numa lotação de seis peixes/aquário. O período experimental foi de 73 dias.

Os aquários, foram dotados de sistema de recirculação de água, com um biofiltro de $250 \mathrm{~L}$ para cada conjunto de 20 aquários, tendo em vista, a preservação da qualidade físico-química da água. A temperatura manteve-se dentro da faixa de conforto para a espécie, 24,0 a $27,0^{\circ} \mathrm{C}$, por meio de sistema de termostato digital. Semanalmente foram efetuadas análises físico-químicas da água, com determinação do oxigênio dissolvido e $\mathrm{pH}$. Para retirada de eventuais sobras de rações e acúmulo de fezes, efetuaramse sifonagens semanais dos aquários, resultando na renovação de aproximadamente $20 \%$ do volume total de água do sistema.

Confeccionou-se uma dieta purificada referência, à base de albumina e gelatina, com $32 \%$ de proteína bruta e $3300 \mathrm{kcal} / \mathrm{kg}$ de energia digestível, destituída de vitamina $\mathrm{C}$ e ferro (Tabela 1). À essa dieta aditiramse níveis de $125 ; 375$ e $1115 \mathrm{mg} / \mathrm{kg}$ de vitamina C (35\% ativa) e 30; 90 e $270 \mathrm{mg}$ de ferro, na forma de sulfato ferroso heptaidratado $(33,10 \%$ ferro $)$.

O suplemento vitamínico e mineral utilizado, era isento de vitamina $\mathrm{C}$ e ferro, sendo considerada como fonte desses, somente as quantidades adicionadas à dieta. Foram determinadas a porcentagem de proteína bruta, extrato etéreo, fibra buta e matéria seca das dietas, segundo a AOAC (1990).
As dietas foram peletizadas e posteriormente fracionadas em dois diâmetros, 1,70 mm e 3,36 mm, sendo utilizadas de acordo com o tamanho dos animais. Os peixes foram arraçoados diariamente nos horários de 8h30, 11h30, 14h30 e 17h30. Em cada arraçoamento, as dietas foram oferecidas de 3 a 4 vezes, na tentativa de se alcançar a saciação.

No início do experimento, foram excluídos do lote inicial, 20 peixes, com o objetivo de se analisar a composição químico-bromatológica da carcaça. Ao final do período experimental, os peixes foram pesados e calculou-se o ganho de peso de cada. Posteriormente, à pesagem, retiraram-se três deles de cada repetição, 12/tratamento, para coleta de fígado. Avaliaram-se as amostras, quanto à coloração e, depois, pesadas para determinação do índice hepatosomático (porcentagem do fígado em relação ao peso corporal). Após as extrações de fígado e vísceras, esses peixes foram utilizados para análise químico-bromatológica da carcaça.

Tabela 1 - Composição percentual da ração purificada referência

Table 1 - Percentual composition of the reference purified diet

\begin{tabular}{|c|c|}
\hline $\begin{array}{l}\text { Ingrediente } \\
\text { Ingredient }\end{array}$ & $\%$ \\
\hline Albumina & 27,80 \\
\hline Albumin & \\
\hline Gelatina & 10,00 \\
\hline Gelatin & \\
\hline Amido de milho & 45,95 \\
\hline Corn starch & \\
\hline Celulose & 5,40 \\
\hline Cellulose & \\
\hline $\begin{array}{l}\text { Antioxidante-BHT } \\
\text { Antioxidant }\end{array}$ & 0,02 \\
\hline $\begin{array}{l}\text { Óleo de soja } \\
\text { Soybean oil }\end{array}$ & 5,00 \\
\hline Fosfato bicálcico & 5,33 \\
\hline $\begin{array}{l}\text { Dicalcium phosphate } \\
\text { Suplemento vitamínico e mineral } \\
\text { Vitamin and mineral mix }\end{array}$ & 0,50 \\
\hline Total & 100,00 \\
\hline
\end{tabular}

Suplemento vitamínico e mineral (vitamin and mineral mix): vitamina A (vitamin A), 1.200.000 Ul; vitamina $D_{3}\left(\right.$ vitamin $\left.D_{3}\right), 200.000 \mathrm{UI}$; vitamina $\mathrm{E}$ (vitamin $E), 12.000 \mathrm{mg}$; vitamina $\mathrm{K}_{3}\left(\right.$ vitamin $\left.K_{3}\right), 2.400 \mathrm{mg}$; vitamian $B_{1}\left(\right.$ vitamin $\left.B_{1}\right), 4.800 \mathrm{mg}$; vitamina $B_{2}\left(\right.$ vitamin $\left.B_{2}\right), 4.800 \mathrm{mg}$; vitamian $B_{12}$ (vitamin $\left.B_{12}\right), 4.800$ mcg; vitamina $B_{6}\left(\right.$ vitamin $\left.B_{6}\right), 4.800 \mathrm{mg}$; vitamina C (vitamin C), ZERO; pantotenato de calcio (calcium), $12.000 \mathrm{mg}$; niacina (niacin), $24.000 \mathrm{mg}$; ácido fólico (folic acid), $1.200 \mathrm{mg}$; biotina (biotin), $48 \mathrm{mg}$; cloreto de colina (choline), $108 \mathrm{~g}$; cobalto (cobalt), $10 \mathrm{mg}$; cobre (cooper), $3.000 \mathrm{mg}$; ferro (iron), ZERO; iodo (iodine), $100 \mathrm{mg}$; manganês (manganese), $20.000 \mathrm{mg}$; selênio (selenium), $100 \mathrm{mg}$; zinco (zinc), $3.000 \mathrm{mg}$; veículo q.s.p., $1.000 \mathrm{mg}$. 
Para determinação dos índices das variáveis hematológicas, foram retirados três peixes/aquário, 12 por tratamento. Os peixes foram anestesiados com benzocaína ( $1 \mathrm{~g} / 15 \mathrm{~L}$ de água) e sangrados com auxílio de seringa de 1,0 mL através da veia caudal, para determinação do número de hemácias, leucócitos e trombócitos. Para isso, utilizando-se, como corante e diluente, a solução de azul de toluídina a $0,01 \%$ em câmara de Neubauer. A hemoglobina foi determinada pelo método da cianometahemoglobina. As variáveis acima apresentadas foram avaliadas utilizando-se as técnicas descritas por Jain (1986).

A porcentagem de hematócrito foi determinada utilizando-se a centrífuga para microhematócrito. $\mathrm{O}$ diferencial de leucócitos foi efetuado em 100 células com lâminas coradas pelo método de Rosenfeld modificado. A proteína plasmática total foi mensurada, através do refratômetro manual para proteína.

Para a avaliação macroscópica do fígado dos peixes, nos diferentes tratamentos, foram analisados três animais por repetição, ou seja, 12 peixes por tratamento. Esses foram anestesiados e, no sentido de permitir a exposição dos órgãos internos, executaram-se duas incisões dorso-ventrais: uma próxima ao opérculo e outra, na abertura do poro urogenital. Realizou-se, também, uma incisão paralela ao dorso, na região abdominal ventral, propiciando, deste modo, o rebatemento de toda a musculatura.

Após esse procedimento, os órgãos do sistema digestório foram extraídos e o fígado, separado para avaliação macroscópica. Com auxílio de lupa, realizou-se a análise individualizada de cada exemplar.

Os resultados dessa pesquisa foram estudados servindo-se da técnica da análise de variância para experimento, em esquema fatorial, com tratamento adicional (controle). Esta análise foi complementada com o estudo de contrastes ortogonais, com a comparação do grupo controle com os demais, e com o desdobramento da interação, sempre que significativa. Estas análises foram implementados utilizando-se o procedimento GLM do programa computacional SAS (SAS, 1985). Para o estudo da mortalidade, foi utilizado o procedimento GENMOD do programa SAS, com a técnica de modelos lineares generalizados (McCullagh \& Nelder, 1989), assumindo-se a distribuição binomial e função de ligação canônica. As conclusões foram obtidas considerando-se o nível de $5 \%$ de significância.

\section{Resultados e Discussão}

As variáveis de qualidade de água se mantiveram dentro da faixa de conforto para a espécie, com valores médios de temperatura, oxigênio dissolvidoe $\mathrm{pH}$ de 24,56 $\pm 1,50^{\circ} \mathrm{C} ; 5,50 \pm 0,25 \mathrm{mg} / \mathrm{Le} 7,00 \pm 0,30$; respectivamente. Com base nesses valores, podemos concluir que não houve influência dos fatores físico-químicos analisados nas variáveis, avaliadas nessa pesquisa.

Os valores médios de ganho de peso, conversão alimentar, índice hepatosomático e porcentagem de sobrevivência estão exibidos na Tabela 2. Ainda que a literatura relate a ação do ácido ascórbico no metabolismo do ferro, e os efeitos fisiológicos desses, os resultados da análise estatística revelaram, que o ganho de peso, a conversão alimentar e a porcentagem de sobrevivência não foram influenciados pelos diferentes níveis de suplementação de vitamina $\mathrm{C}$ e ferro e que, também, não houve interação significativa entre os fatores para as variáveis apresentadas.

Embora não significativo, o aumento no nível de ferro determinou tendência de queda, no ganho de peso dos alevinos de 8,95 e $10,03 \%$, respectivamente, para os níveis de suplementação de 90 e $270 \mathrm{mg} / \mathrm{kg}$ de ração. Essa tendência reforça as observações feitas por Gatlin \& Wilson (1986), destacando que o excesso desse pode ser nociso aos peixes. Desjardins et al. (1987) avaliando o efeito da suplementação de ferro, qualidade do óleo e da sobrecarga desse mineral no crescimento e respostas fisiológicas, determinaram, com base nas variáveis de crescimento, mortalidade e avaliações histológicas, que o nível tóxico de ferro para a truta-arco-íris, varia entre 86 e $265 \mathrm{mg}$ de ferro/kg de dieta. NRC (1993) ressalta que os maiores efeitos da toxicidade do ferro são: a queda no crescimento, aumento da mortalidade, diarréia e alterações histopatológicas nas células do fígado. Efeitos negativos do ferro na higidez dos peixes, também foram sugerido por Salte et al. (1994).

Observações contrárias também têm sido determinadas. Lim et al. (1996) avaliaram a exigência de ferro para o bagre do canal, utilizando o ferro-metionina e sulfato ferroso, como fontes desse mineral. Os autores observaram queda no ganho de peso somente para o tratamento ausente de suplementação e que, de forma oposta, também não significativa, o aumento de 20 para 60 e $180 \mathrm{mg} \mathrm{Fe} / \mathrm{kg}$ de ração, na forma de sulfato, determinou discreto aumento de peso para

R. Bras. Zootec., v.31, n.6, p.2149-2156, 2002 
Tabela 2 - Ganho médio de peso, conversão alimentar, índice hepatossomático (IHS) e porcentagem de sobrevivência de alevinos revertidos de tilápia do Nilo alimentados com dietas contendo diferentes níveis de vitamina $\mathrm{C}$ e ferro por 10 semanas

Table 2 - Average weight gain, hepatossomatic index, feed conversion and survival of sex reverted fingerlings of Nile tilapia fed diets containing different levels of vitamin $C$ and iron for 10 weeks

\begin{tabular}{|c|c|c|c|c|c|}
\hline $\operatorname{Vit~C}^{1}$ & Ferro $^{2}$ & $\mathrm{GP}^{3}$ & $\mathrm{CA}^{4}$ & IHS & $\mathrm{SBV}^{5}$ \\
\hline \multirow[t]{2}{*}{0} & 0 & 577,07 & 1,62 & 1,99 & 100,00 \\
\hline & 30 & 573,43 & 1,59 & 2,99 & 95,83 \\
\hline \multirow[t]{3}{*}{125} & 90 & 550,09 & 1,71 & 2,77 & 100,00 \\
\hline & 270 & 557,92 & 1,63 & 2,03 & 100,00 \\
\hline & 30 & 477,50 & 1,70 & 1,77 & 91,67 \\
\hline \multirow[t]{3}{*}{375} & 90 & 624,22 & 1,67 & 2,16 & 100,00 \\
\hline & 270 & 589,90 & 1,60 & 1,75 & 100,00 \\
\hline & 30 & 584,58 & 1,65 & 2,21 & 100,00 \\
\hline \multirow[t]{2}{*}{1115} & 90 & 621,14 & 1,64 & 1,99 & 100,00 \\
\hline & 270 & 468,19 & 1,77 & 2,07 & 95,00 \\
\hline \multicolumn{2}{|c|}{ A vs $F^{7}$} & $\mathrm{~ns}$ & $\mathrm{~ns}$ & $\mathrm{~ns}$ & $\mathrm{~ns}$ \\
\hline \multicolumn{2}{|c|}{ Vit C $^{8}$} & $\mathrm{~ns}$ & $\mathrm{~ns}$ & 0,01 & $\mathrm{~ns}$ \\
\hline \multicolumn{2}{|l|}{125} & 563,87 & 1,23 & 2,59 & 98,61 \\
\hline \multicolumn{2}{|l|}{375} & 560,78 & 1,24 & 1,89 & 99,33 \\
\hline \multirow[t]{5}{*}{1115} & & 557,97 & 1,26 & 2,09 & 97,22 \\
\hline & $\mathrm{Fe}^{9}$ & $\mathrm{~ns}$ & $\mathrm{~ns}$ & 0,05 & $\mathrm{~ns}$ \\
\hline & 30 & 598,78 & 1,24 & 2,32 & 100,00 \\
\hline & 90 & 545,17 & 1,25 & 2,31 & 98,33 \\
\hline & 270 & 538,67 & 1,25 & 1,95 & 95,83 \\
\hline \multicolumn{2}{|c|}{ Vit Cx Ferro ${ }^{10}$} & $\mathrm{~ns}$ & $\mathrm{~ns}$ & 0,05 & $\mathrm{~ns}$ \\
\hline
\end{tabular}

${ }^{1}$ Vitamina C mg/kg dieta (Vitamin C mg/kg diet); ${ }^{2}$ Ferro mg/kg dieta (Iron $\mathrm{mg} / \mathrm{kg}$ diet); ${ }^{3}$ Ganho de peso g (Weight gain g); ${ }^{4}$ Conversão alimentar (Feed conversion); 5 Sobrevivência \% (Survival \%): ${ }^{7}$ Adicional vs Fatores, nível P (Additional vs Factors, P level); 8 Efeito da Vitamina C, nível P (Effect of vitamin C, P level); ${ }^{9}$ Efeito do Ferro, nível P (Effect of iron, Pleve); ${ }^{10}$ Interação Vitamina C e Ferro (Vitamin $C$ and Iron interaction).

os animais. Barros et al. (2000) avaliando a suplementação de ferro, na forma de sulfato ferroso, em dietas contendo diferentes níveis de inclusão de farelo de algodão, observaram que o incremento no nível de suplementação de ferro $(40 ; 336$ e $671 \mathrm{mg} / \mathrm{kg}$ de ração) determinou aumento linear significativo do ganho de peso, consumo de ração e taxa de eficiência protéica para o tratamento, à base de farelo de soja. Os autores também destacaram controvérsia de resultados apresentados na literatura, principalmente, com relação ao ganho de peso.

Não foram detectados sinais clínicos de deficiência nos alevinos alimentados com dieta ausente de vitamina C. Esses resultados contrastam com os obtidos por Lovell (1973) e Hilton et al. (1978) porém, estão concordantes com Sato et al. (1978) e Lim et al. (2000). A não detecção de sinais de deficiência nesse estudo pode ser devido ao tempo de experimento. Os autores que descrevem sinais clínicos de deficiência revelaram, que os mesmos se manifestaram, em média, entre a $12^{\mathrm{a}}$ e $20^{\mathrm{a}}$ semana experimental.

O efeito da interação entre os níveis de vitamina $\mathrm{C}$ e de ferro foi significativo $(\mathrm{p}<0,05)$ para o índice hepatosomático (IHS). De maneira geral, entretanto, tendo em vista os níveis não equidistantes dos fatores estudados, percebe-se tendência geral de queda no índice de IHS com o aumento dos níveis de vitamina $\mathrm{C}$ e de ferro. Andersen et al. (1998) detectaram aumento significativo do índice hepatosomático para o salmão do Atlântico, alimentado com dietas suplementadas com ferro e vitamina $\mathrm{C}$ após a $20^{\mathrm{a}}$ semana experimental. Os resultados demonstraram que esse efeito foi devido à suplementação com ambos, ferro $(400 \mathrm{mg} / \mathrm{kg})$ e vitamina C $(150 \mathrm{mg} / \mathrm{kg})$; essa, na forma de ácido ascórbico, protegido com etil celulose. Resultados contrários, aos obtidos nesse estudo, para a vitamina $\mathrm{C}$ e ferro.

Analisando-se os dados de porcentagem de sobrevivência apresentados na Tabela 2, nota-se que os tratamentos $125 \mathrm{C} / 30 \mathrm{Fe} ; 375 \mathrm{C} / 30 \mathrm{Fe}$ e $1115 \mathrm{C} / 270 \mathrm{Fe}$ apresentaram média de $5,83 \%$ de mortalidade. Todavia não estatisticamente diferente dos demais tratamentos $(p>0,10)$. Cabe ressaltar ainda que a avaliação visual dos animais permite-nos inferir que a mortalidade ocorrida foi em conseqüência de confrontos entre animais, característica marcante da espécie em estudo, e não em função dos tratamentos.

Os valores médios de hemácias, hematócrito e hemoglobina estão apresentados na Tabela 3. Convém destacar que a porcentagem de hematócrito e a concentração de hemoglobina foram significativamente diferentes, comparando-se o tratamento adicional versus os demais, e o nível de vitamina $\mathrm{C}$ influenciou significativamente a porcentagem de hematócrito.

Embora não de forma significativa, os resultados observados no tratamento ausente de vitamina $\mathrm{C} \mathrm{e}$ ferro, corroboram com os descritos na literatura. Isso porque, a ausência de ferro prejudica a formação das hemácias. Kaneko (1980) destacou que, na ausência de ferro, as células vermelhas são pequenas e o nível 
Tabela 3 - Valores médios de hemácias, hematócrito e hemoglobina de alevinos revertidos de tilápia do Nilo alimentados com dietas contendo diferentes níveis de vitamina $\mathrm{C}$ e ferro por 10 semanas

Table 3 - Mean red blood cell count, hematocrit and hemoglobin of sex reverted of Nile tilapia firgerlings fed diets containing diferent levels of vitamin $C$ and iron for 10 weeks

\begin{tabular}{|c|c|c|c|c|}
\hline Vit $C^{1}$ & Ferro $^{2}$ & $\mathrm{Hem}^{3}$ & $\mathrm{Hct}^{4}$ & $\mathrm{Hb}^{5}$ \\
\hline \multirow[t]{2}{*}{0} & 0 & 1,60 & 27 & 6,20 \\
\hline & 30 & 1,92 & 29 & 6,90 \\
\hline \multirow[t]{3}{*}{125} & 90 & 1,89 & 30 & 7,30 \\
\hline & 270 & 1,98 & 29 & 7,40 \\
\hline & 30 & 1,88 & 33 & 7,50 \\
\hline \multirow[t]{3}{*}{375} & 90 & 1,85 & 32 & 7,10 \\
\hline & 270 & 1,86 & 33 & 7,50 \\
\hline & 30 & 1,79 & 33 & 7,30 \\
\hline \multirow[t]{2}{*}{1115} & 90 & 1,73 & 31 & 7,30 \\
\hline & 270 & 1,86 & 33 & 7,30 \\
\hline$A$ vs $F^{6}$ & & $\mathrm{~ns}$ & 0,05 & 0,05 \\
\hline $\operatorname{Vit~C}^{7}$ & & $\mathrm{~ns}$ & 0,05 & $\mathrm{~ns}$ \\
\hline 125 & & 1,92 & 29 & 7,20 \\
\hline 375 & & 1,86 & 33 & 7,40 \\
\hline \multirow[t]{6}{*}{1115} & & 1,79 & 32 & 7,20 \\
\hline & $\mathrm{Fe}^{8}$ & $\mathrm{~ns}$ & $\mathrm{~ns}$ & $\mathrm{~ns}$ \\
\hline & Iron & & & \\
\hline & 30 & 1,90 & 32 & 7,20 \\
\hline & 90 & 1,86 & 31 & 7,20 \\
\hline & 270 & 1,82 & 31 & 7,40 \\
\hline Vit C x Ferro 9 & & $\mathrm{~ns}$ & $\mathrm{~ns}$ & $\mathrm{~ns}$ \\
\hline Vit $C x$ Iron & & & & \\
\hline
\end{tabular}

1 Vitamina C mg/kg dieta (Vitamin C mg/kg diet); ${ }^{2}$ Ferro $\mathrm{mg} / \mathrm{kg}$ dieta (Iron mg/kg diet); ${ }^{3}$ Hemácias, $10^{6} / \mathrm{mL}$ (red blood cell); ${ }^{4}$ Hematócrito $\%$ (hematocrit); 5 Hemoglobina, g/dL (hemoglobin); 6 Adicional vs Fatores, nível P (Additional vs Factors, P level) $;^{7}$ Efeito da vitamina C, nível P (Effect of Vitamin C, P level); ${ }^{8}$ Efeito do Ferro, nível P (Effect of iron, $P$ level); ${ }^{9}$ Interação Vitamina $C$ e Ferro (Vitamin $C$ and Iron interaction).

de hemoglobina é baixo. Smith (1997) também descreveu, como efeitos fisiológicos da ausência desse mineral, a limitada formação da hemoglobina, bem como a inibição da formação de enzimas ferro dependentes. Lim et al. (2000) estudando a suplementação de vitamina $\mathrm{C}$ e ferro para alevinos de bagre do canal observaram interação significativa entre esses fatores, para a síntese de hemácias e porcentagem de hematócritos.

No presente estudo, para o tratamento adicional, detectou-se tendência de queda, em média de 13,97\%, no número de hemácias produzidas, quando comparado aos demais tratamentos. Avaliando-se a porcen- tagem de hematócrito e a concentração de hemoglobina para esse mesmo tratamento, notou-se a queda significativa nesses valores. Esses dados caracterizam anemia microcítica e hipocrômica. Igualmente, Lim et al. (1996) alimentando alevinos de bagre do canal com dietas purificadas, à base de albumina e deficientes em ferro determinaram desenvolvimento de anemia microcítica hipocrômica caracterizada pelo decréscimo da hemoglobina, hematócrito, volume corpuscular médio e hemoglobina corpuscular média.

Avaliando-se o efeito do ferro no crescimento e respostas fisiológicas da truta-arco-íris Desjardins et al. (1987) observaram que a concentração de hemoglobina aumentou, mas não de forma significativa, com o acréscimo no nível de suplementação desse mineral na dieta. Resultados semelhantes, porém de forma significativa, foram obtidos por Ukawa et al. (1994) avaliando o efeito da suplementação de ferro, na forma de ferro proteinato, em dietas a base de concentrado protéico de soja sobre as variáveis hematológicas do yellowtail (Seriola lalandi). Os autores observaram que a ausência de suplementação de ferro determinou de forma significativa, índices reduzidos para a porcentagem de hematócritos e concentração de hemoglobina, comparados com os suplementados. Da mesma forma, Lim \& Klesius (1997) obtiveram valores significativamente inferiores para o hematócrito (\%) e para a contagem de células vermelhas totais $(\mathrm{n} / \mathrm{mL})$, ao compararem a suplementação de ferro com a ausência desse, em dietas purificadas à base de albumina, para o bagre do canal.

Houve efeito significativo da inclusão da vitamina C na porcentagem de hematócrito. Constatou-se que o incremento dessa, determinou aumento na porcentagem de hematócrito. $O$ efeito da vitamina $C$ na porcentagem de hematócritos também foi observado por Mustin \& Lovell (1992). Esses avaliaram diferentes níveis $(0 ; 15 ; 30 ; 60$ e $120 \mathrm{mg} / \mathrm{kg})$ e fontes de ascorbil-2-monofosfato (AAP-Na, AAP-Mg) em dietas para o bagre do canal. Similar ao ocorrido nesse estudo, a porcentagem de hematócrito foi significativamente menor no tratamento ausente de suplementação. A inclusão de níveis de vitamina C (40; 400; 2000 e 4000 mg/kg) em dietas para salmão do Atlântico objetivando avaliar a imunidade e resistência a doença foi estudada por Waagbo et al. (1993). Os autores observaram, de forma distinta aos achados nesse estudo, que o nível de hematócrito em peixes não tratados foi estatisticamente maior no 
nível de $40 \mathrm{mg} / \mathrm{kg}$ de vitamina C (ascorbato-2monofosfato), após onze semanas da vacinação. Lim et al. (2000) não encontraram efeito significativo dos níveis de vitamina $\mathrm{C}$ na porcentagem de hematócrito. Entretanto, os autores determinaram efeito dos níveis de ferro e interação significativa entre a vitamina $C$ e o ferro para essa variável.

Valores médios de volume globular médio(VGM), concentração de hemoglobina globular média (CHGM) e proteína plasmática total estão apresentados na Tabela 4.

Embora não tenha havido significância na comparação do tratamento ausente de suplementação com os demais para o VGM, pode-se inferir que houve tendência de queda de $8,07 \%$ para o tratamento adicional. Essa resposta pode ser devido aos valores de hematócrito e hemácias apresentados por esse tratamento. Baixos valores de VGM foram igualmente detectados por Lim et al. (1996) para alevinos de bagre do canal alimentados com diferentes níveis e fontes de ferro por 8 semanas. Esses autores observaram ainda, que o tratamento ausente de suplementação não diferiu estatisticamente dos níveis de 5 e 10 mg/kg de suplementação com ferrometionina.

Valores de volume globular médio e de concentração de hemoglobina globular média foram avaliados por Ukawa et al. (1994) para yellowtail, que foram alimentados com diferentes níveis de suplementação de ferro proteinato em dietas à base de concentrado protéico de soja e farinha de peixe. Esses observaram acréscimo do VGM e CHGM com o aumento dos níveis de ferro proteinato na dieta porém, de forma geral, variações hematológicas indesejávais ocorreram com a inclusão de níveis acima de $4000 \mathrm{mg} / \mathrm{kg}$. Sakamoto \& Yone (1978) avaliaram os efeitos hematológicos da ausência e inclusão de $200 \mathrm{mg} / \mathrm{kg}$ de ferro em dietas para carpa e observaram diferenças significativas para o VGM e CHGM de 21,16 e $5,60 \%$, respectivamente.

Da mesma forma que a porcentagem de hematócrito, os valores de volume globular médio obtidos nesse estudo, também foram influenciados significativamente com o aumento da inclusão da vitamina C. A concentração de hemoglobina globular média comportou-se similarmente à concentração de hemoglobina uma vez que, a mesma é a razão dessa, com o hematócrito.

A concentração de proteína plasmática total não sofreu influência dos níveis de vitamina $\mathrm{C}$ e ferro. De
Tabela 4 - Valores médios do volume globular médio, concentração de hemoglobina globular média e proteína plasmática total de alevinos revertidos de tilápia do Nilo alimentados com dietas contendo diferentes níveis de vitamina C e ferro por 10 semanas

Table 4 - Average corpuscular volume, mean corpuscular hemoglobin concentration and total plasma protein of sex reverted Nile tilapia fingerlings fed diets containing different levels of vitamin $C$ and iron for 10 weeks

\begin{tabular}{|c|c|c|c|c|}
\hline $\mathrm{Vit}^{1}$ & Ferro $^{2}$ & VGM $^{3}$ & $\mathrm{CHGM}^{4}$ & $\mathrm{PPT}^{5}$ \\
\hline \multirow[t]{2}{*}{0} & 0 & 156,00 & 18,76 & 4,73 \\
\hline & 30 & 155,00 & 23,54 & 4,26 \\
\hline \multirow[t]{3}{*}{125} & 90 & 160,00 & 24,41 & 4,26 \\
\hline & 270 & 146,00 & 25,71 & 3,86 \\
\hline & 30 & 177,00 & 22,88 & 4,53 \\
\hline \multirow[t]{3}{*}{375} & 90 & 174,00 & 22,38 & 4,46 \\
\hline & 270 & 177,00 & 22,82 & 4,26 \\
\hline & 30 & 184,00 & 22,14 & 4,33 \\
\hline \multirow{2}{*}{1115} & 90 & 178,00 & 22,56 & 4,26 \\
\hline & 270 & 176,00 & 22,75 & 4,73 \\
\hline A vs $F^{6}$ & & $\mathrm{~ns}$ & 0,01 & $\mathrm{~ns}$ \\
\hline Vit $C^{7}$ & & 0,05 & $\mathrm{~ns}$ & $\mathrm{~ns}$ \\
\hline 125 & & 154,00 & 24,55 & 4,13 \\
\hline 375 & & 176,00 & 22,69 & 4,42 \\
\hline \multirow[t]{5}{*}{1115} & & 180,00 & 22,48 & 4,26 \\
\hline & $\mathrm{Fe}^{8}$ & $\mathrm{~ns}$ & $\mathrm{~ns}$ & $\mathrm{~ns}$ \\
\hline & 30 & 172,00 & 22,86 & 4,37 \\
\hline & 90 & 171,00 & 23,12 & 4,31 \\
\hline & 270 & 166,00 & 23,76 & 4,13 \\
\hline Vit $\mathrm{C} \times \mathrm{Fe}^{9}$ & $\mathrm{~ns}$ & $\mathrm{~ns}$ & $\mathrm{~ns}$ & \\
\hline
\end{tabular}

1 vitamina $\mathrm{C} \mathrm{mg} / \mathrm{kg}$ dieta (vitamin $\mathrm{C} \mathrm{mg} / \mathrm{kg}$ diet); ${ }^{2}$ ferro $\mathrm{mg} / \mathrm{kg}$ dieta (iron $\mathrm{mg} / \mathrm{kg}$ diet); ${ }^{3}$ volume globular médio, $\mathrm{fL}$ (average globular volume); 4 concentração de hemoglobina globular média, $\mathrm{mL} / \mathrm{dL}$ (average corpuscular hemoglobin concentration); 5 proteína plasmática total, $\mathrm{mg} / \mathrm{dL}$ (total plasma protein); ${ }^{6}$ adicional vs fatores, nível $\mathrm{P}$ (additional vs factors, $P$ level); ${ }^{7}$ efeito da vitamina $C$, nível $\mathrm{P}$ (effect of vitamin $C$, $P$ level); 8 efeito do ferro, nível P (effect of iron, $P$ level); 9 interação vitamina $\mathrm{C}$ e ferro (vitamin $C$ and iron interaction).

acordo com Swenson (1996) as proteínas plasmáticas são identificadas como albumina, globulinas e fibrinogênio, podendo estar marcadamente reduzidas nas alterações hepáticas graves ou dietas prolongadas com deficiência de proteína.

Os resultados desse estudo permitem concluir, de forma indireta, que, embora tenham sido utilizados níveis supostamente elevados de ferro nas dietas, esses não determinaram prejuízo aparente e o nível 
de proteína e energia das rações foi adequado para manter o desempenho dos peixes. Desjardins et al. (1987) estudando o efeito de diferentes níveis suplementares de sulfato ferroso heptaidrato em dietas purificadas para a truta arco íris, determinaram que os níveis de proteínas plasmáticas, similarmente aos resultados desse estudo, não foram significativamente influenciados pelos níveis de ferro utilizados.

Os valores de leucócitos, bem como a diferenciação, linfócitos e neutrófilos, estão apresentados na Tabela 5. Não houve efeito dos diferentes níveis de suplementação de vitamina $\mathrm{C}$ e ferro nessa série leucocitária.

Embora de forma não significativa, observou-se que houve leve tendência de aumento no número de neutrófilos, sendo essa, em média de $8,71 \%$ em níveis de vitamina $\mathrm{C}$ acima da exigência proposta para a espécie.

A literatura apresenta 3,00\% como valor mínimo de neutrófilos para a tilápia do Nilo (Tavares-Dias \& Faustino, 1998). Para a Oreochromis aureus e para a $O$. mossambicus, os valores médios respectivos são: $1,60 \%$ e 7,80 \% (Silveira \& Rigores, 1989; Nussey et al., 1995). Já para a Tilapia zilli esse valor se encontra na média de 24,50 \% (Ezzat et al., 1974). Lovell (1998) ressalta que a deficiência das vitaminas antioxidantes, entre elas a vitamina $\mathrm{C}$, geralmente causa redução na resistência dos peixes. Apesar de já descrita a ação da vitamina $C$ na resistência a doenças, faltam pesquisas que avaliem esse efeito estimulatório na produção de leucócitos.

Analisou-se a composição químico-bromatológica da carcaça de alevinos de tilápia do Nilo no início e final do período experimental. Constatou-se que, em média, os peixes apresentaram ao final do período experimental valores de $95,82 \% ; 75,18 \% ; 9,10 \%$ e $5,84 \%$ para matéria seca, proteína bruta, extrato etéreo e material mineral, respectivamente, e que houve tendência de acréscimo dos níveis de matéria mineral com o aumento dos níveis de inclusão de ferro nas dietas experimentais. Barros et al. (2000), de forma oposta ao ocorrido nesse estudo, não encontraram tendência de alterações da porcentagem da matéria mineral da carcaça de alevinos de bagre do canal, quando o nível de suplementação de ferro, na forma de sulfato ferroso heptaidratado, passou de zero para 336 ou $671 \mathrm{mg} / \mathrm{kg}$.

Não foram detectados sinais clínicos patológicos no fígado dos peixes submetidos aos diferentes tratamentos experimentais, que apresentaram coloração, formato e consistência característicos deste órgão.
Tabela 5 - Valores médios de leucócitos e percentuais de linfócitos e neutrófilos de alevinos revertidos de tilápia do Nilo alimentados com dietas contendo diferentes níveis de vitamina $\mathrm{C} \mathrm{e}$ ferro por 10 semanas

Table 5 - Average values of leukocytes, lymphocytes and neutrophils of sex reverted Nile tilapia fingerlings fed diets containing different levels of vitamin $C$ and iron for 10 weeks

\begin{tabular}{|c|c|c|c|c|}
\hline Vit $C^{1}$ & $\mathrm{Fe}^{2}$ & Leuc $^{3}$ & $\operatorname{Linf}^{4}$ & Neutr ${ }^{5}$ \\
\hline \multirow[t]{2}{*}{0} & 0 & 1,02 & 87,33 & 7,67 \\
\hline & 30 & 0,71 & 93,00 & 7,34 \\
\hline \multirow[t]{3}{*}{125} & 90 & 1,16 & 90,67 & 7,00 \\
\hline & 270 & 1,10 & 88,00 & 6,67 \\
\hline & 30 & 0,84 & 92,00 & 7,67 \\
\hline \multirow[t]{3}{*}{375} & 90 & 1,00 & 91,33 & 6,67 \\
\hline & 270 & 0,66 & 90,00 & 8,00 \\
\hline & 30 & 0,87 & 94,67 & 7,67 \\
\hline \multirow[t]{2}{*}{1115} & 90 & 0,82 & 93,33 & 7,67 \\
\hline & 270 & 0,88 & 89,00 & 8,00 \\
\hline \multicolumn{2}{|l|}{ A vs $F^{6}$} & $\mathrm{~ns}$ & $\mathrm{~ns}$ & $\mathrm{~ns}$ \\
\hline \multicolumn{2}{|l|}{ Vit $C^{7}$} & $\mathrm{~ns}$ & $\mathrm{~ns}$ & $\mathrm{~ns}$ \\
\hline \multicolumn{2}{|l|}{125} & 0,99 & 90,55 & 7,00 \\
\hline \multicolumn{2}{|l|}{375} & 0,83 & 91,11 & 7,44 \\
\hline \multirow[t]{5}{*}{1115} & & 0,86 & 92,33 & 7,78 \\
\hline & $\mathrm{Fe}^{8}$ & $\mathrm{~ns}$ & $\mathrm{~ns}$ & $\mathrm{~ns}$ \\
\hline & 30 & 0,81 & 93,22 & 7,55 \\
\hline & 90 & 0,99 & 91,78 & 7,11 \\
\hline & 270 & 0,88 & 89,00 & 7,55 \\
\hline \multicolumn{2}{|c|}{ Vit C $x$ Ferro $^{9}$} & $\mathrm{~ns}$ & $\mathrm{~ns}$ & $\mathrm{~ns}$ \\
\hline
\end{tabular}

${ }^{1}$ vitamina $\mathrm{C} \mathrm{mg} / \mathrm{kg}$ dieta (vitamin $\mathrm{C} \mathrm{mg} / \mathrm{kg}$ diet); ${ }^{2}$ ferro $\mathrm{mg} / \mathrm{kg}$ dieta (iron $\mathrm{mg} / \mathrm{kg}$ diet); 3 leucócitos, $10^{5}$ (leukocytes); 4 linfócitos, $\mathrm{mL} / \mathrm{dL}$ (Iymphocytes); ${ }^{5}$ neutrófilos, mg/dL (neutrophils); ${ }^{6}$ adicional vs fatores, nível P (additional vs factors, $P$ leven); ${ }^{7}$ efeito da vitamina C, nível $\mathrm{P}$ (effect of vitamin C, $P$ level); 8 efeito do ferro, nível $\mathrm{P}$ (effect of iron, $P$ level); ${ }^{9}$ interação vitamina $C$ e ferro (vitamin $C$ and iron interaction).

\section{Conclusões}

A ausência de vitamina $\mathrm{C}$ e ferro, nas dietas, propiciou o aparecimento de anemia microcítica e hipocrômica aos alevinos de tilápia do Nilo.

A vitamina $\mathrm{C}$ suplementada em dosagens elevadas, estimulou a liberação de eritrócitos imaturos na corrente sangüínea.

Níveis de vitamina $\mathrm{C}$ e ferro acima das exigências nutricionais descritas para a espécie não determinam efeito detrimental no desempenho produtivo, produção de proteínas plasmáticas e aspectos morfológicos do fígado.

Níveis de vitamina $\mathrm{C}$ e ferro não determinaram alterações na composição mineral da carcaça de alevinos de tilápia do Nilo. 


\section{Agradecimento}

À Fundação de Amparo à Pesquisa do Estado de São Paulo - FAPESP, pelo apoio financeiro, e à Supre Mais Produtos Bioquímicos Ltda, pela sustentação científica.

\section{Literatura Citada}

ASSOCIATION OF OFFICIAL ANALYTICAL CHEMISTS AOAC. Official methods of analysis. 14.ed. Arlington: 1990. 1097p.

BARROS, M.M.; LIM, C.; EVANS, J.J. et al. Effect of iron supplementation to cottonseed meal diets on the growth performance of channel catfish, Ictalurus punctatus. Journal of Applied Aquaculture, v.10, p.65-86, 2000.

DESJARDINS, L.M.; HICKS, B.D.; HILTON, J.W. Iron catalyzed oxidation of trout diets and its effect on the growth and physiological response of rainbow trout. Fish Physiology and Biochemistry, v.3, p.173-182, 1987.

DEVLIN, T.M. Manual de bioquímica com correlações químicas. 4.ed. São Paulo: Edgard Blucher, 1998. 1007p.

EZZAT, A.A. Studies on blood characteristics of Tilapia zilli. I. Blood cells. Journal of Fish Biology, v.6., n.1, p.1-2, 1974.

GATLIN, D.M.; WILSON, P.W. Characterization of iron deficiency and the dietary iron requirement of fingerling channel catfish. Aquaculture, v.52, p.191-198, 1986.

GOODWIN, J.; MURPHY, B.; GUILLEMETTE, M. Direct measurement of serum iron and binding capacity. Clinical Chemistry, v.12, p.47-57, 1966.

HILTON, J.W.; CHO, C.Y.; SLINGER, S.J. Effect of graded levels of supplemental ascorbic acid in pratical diets for rainbow trout. Journal Fishiries Research Board Canadian, v.35, p.431-436, 1978.

JAIN, N.C. Schalm's veterinary haematology. 4.ed. Philadelphia: Lea \& Febiger, 1986. 1221p.

KANEKO, J.J. Clinical biochemistry of domestic animals. 3.ed. New York: Academic Press, 1980. p.649-669.

LIM, C.; KLESIUS, P.H. Responses of channel catfish (Ictalurus punctatus) fed iron-deficient and replete diets to Edwardsiella ictaluri challenge. Aquaculture, v.157, p.83-93, 1997.

LIM, C.; KLESIUS, P.H.; LI, M.H. et al. Interaction between dietary levels of iron and vitamin $\mathrm{C}$ on growth, hematology, immune response and resistance of channel catfish (Ictalurus punctatus) to Edwardsiella ictaluri challenge. Aquaculture, v. 185, p.313-327, 2000.

LIM, C.; SEALEY, W.M.; KLESIUS, P.H. Iron methionine and iron sulfate as sources of dietary iron for channel catfish Ictalurus punctatus. Journal of World Aquaculture Society, v.27, p.290-296, 1996.

LOVELL, R.T. Essentiality of vitamin C in feeds for intensively fed caged channel catfish. Journal of Nutrition, v.103, p.134-138, 1973.
LOVELL, R.T. Nutrition and feeding of fish. 2.ed. Massachusetts: Kluwer Academic Publishers, 1998. 267p.

MUSTIN, W.G.; LOVELL, R.T. Na-L-ascorbyl-2monophosphate as a source of NRC (National Research Council), Nutrient requirements of fish. Washington. D.C.: National Academy Press, 1993. 114p.

NUSSEY, G. Effects of cooper on the diferencial white cell counts of the Mosambique tilapia, Oreochromis mossambicus (Cichlidae). Compendio of Biochemistry and Physiology, v.111, n.3, p.381-388, 1995.

SAKAMOTO, S.; YONE, Y. Iron deficiency symptoms of carp. Bulletin of Japanese Society Science Fisheries, v.44, p.1157-1160, 1978

SALTE, R.; RORVIK, K.A.; REED, E. et al. Winter ulcers of the skin in Atlantic salmon, Salmo salar L.: pathogenisis and possible aetiology. Journal of Fish Disease, v.17, p.661665, 1994.

SAS INSTITUTE. SASÒ User's Guide: Statistics. 5.ed. Cary: 1985. 956p.

SATO, M.R.; YOSHINAKA, R.; YAMAMOTO, S. Nonessestiality of ascorbic acid in the diet of carp. Bulletin of Japanese Society Science Fisheries, v.44, p.1151$1156,1978$.

SILVEIRA, R.; RIGORES, C. Caracteristicas hematologicas normales de Oreochromis aureus em cultivo. Revista Latina Acuicultura, v.39, p.54-56, 1989.

SMITH, J.E. Iron metabolism and its disorders. In: KANEKO, J.J., HARVEY, J.W., BRUSS, M.L. (Eds.) Clinical biochemistry of domestic animals. 5.ed. New York: Academic Press, 1997, p.223-39.

SWENSON, M.J. Propriedades fisiológicas e constituintes químicos e celulares do sangue. In: DUKES, H.H.; SWENSON, M.J.; REECE, W.O. (Eds.) Dukes fisiologia dos animais domésticos. 11.ed. Rio de Janeiro: Guanabara Koogan, 1996. p.19-43.

TAVARES-DiAS, M.; FAUSTINO, C.D. Parâmetros hematológicos da tilápia do Nilo Oreochromis niloticus (Cichlidae) em cultivo extensivo. ARS Veterinária, v.14, n.3, p.254-263, 1998.

UKAWA, M.; TAKII, K.; NAKAMURA, M. et al. Effect of iron supplements on a soy protein concentrate diet on hematology of yellowtail. Fisheries Science, v.60, p.165-169, 1994.

WAAGBO, R.; GLETTE, J.; RAA-NILSEN, E. et al. Dietary vitamin $\mathrm{C}$, immunity and disease resistance in Atlantic salmon (Salmo salar). Fish Physiology and Biochemistry, v.12, p.61-73, 1993.
Recebido em: 06/09/01

Aceito em: 16/07/02 